\title{
Transcriptional activator DOT1L putatively regulates human embryonic stem cell differentiation into the cardiac lineage
}

\author{
Varsha Pursani ${ }^{1}$, Deepa Bhartiya ${ }^{1 *}$, Vivek Tanavde ${ }^{2,3}$, Mohsin Bashir $^{4}$ and Prabha Sampath ${ }^{4}$
}

\begin{abstract}
Background: Commitment of pluripotent stem cells into differentiated cells and associated gene expression necessitate specific epigenetic mechanisms that modify the DNA and corresponding histone proteins to render the chromatin in an open or closed state. This in turn dictates the associated genetic machinery, including transcription factors, acknowledging the cellular signals provided. Activating histone methyltransferases represent crucial enzymes in the epigenetic machinery that cause transcription initiation by delivering the methyl mark on histone proteins. A number of studies have evidenced the vital role of one such histone modifier, DOT1L, in transcriptional regulation. Involvement of DOT1L in differentiating pluripotent human embryonic stem (hES) cells into the cardiac lineage has not yet been investigated.
\end{abstract}

Methods: The study was conducted on in-house derived (KIND1) and commercially available (HES3) human embryonic stem cell lines. Chromatin immunoprecipitation (ChIP) was performed followed by sequencing to uncover the cardiac genes harboring the DOT1L specific mark H3K79me2. Following this, dual immunofluorescence was employed to show the DOT1L co-occupancy along with the cardiac progenitor specific marker. DOT1L was knocked down by siRNA to further confirm its role during cardiac differentiation.

Results: ChIP sequencing revealed a significant number of peaks characterizing H3K79me2 occupancy in the proximity of the transcription start site. This included genes like MYOF, NR2F2, NKX2.5, and HAND1 in cardiac progenitors and cardiomyocytes, and POU5F1 and NANOG in pluripotent hES cells. Consistent with this observation, we also show that DOT1L co-localizes with the master cardiac transcription factor NKX2.5, suggesting its direct involvement during gene activation. Knockdown of DOT1L did not alter the pluripotency of hES cells, but it led to the disruption of cardiac differentiation observed morphologically as well as at transcript and protein levels.

Conclusions: Collectively, our data suggests the crucial role of H3K79me2 methyltransferase DOT1L for activation of NKX2.5 during the cardiac differentiation of hES cells.

Keywords: Human embryonic stem cells, Cardiac differentiation, DOT1L, Epigenetics, Gene expression, Histone methyltransferase

\section{Background}

Pluripotent stem cells (PSCs) are blank cells with the ability to differentiate into multiple cell types depending upon the cues provided in vitro. They have open euchromatin and complex epigenetic changes occur when these PSCs become committed. Among these, histone modifications take up the major role of opening

\footnotetext{
* Correspondence: deepa.bhartiya@yahoo.in

${ }^{1}$ Stem Cell Biology Department, ICMR-National Institute for Research in Reproductive Health, J.M. Street, Parel, Mumbai, Maharashtra 400 012, India

Full list of author information is available at the end of the article
}

the chromatin structure for the subsequent transcription activation. A number of studies have started unlocking the molecular mechanisms of these epigenetic factors that precisely orchestrate the development of specific cell types from undifferentiated PSCs to aid in their wide applications. Bivalency PSCs is a central discovery involving an interesting interplay of histone methylations H3K27me3 and H3K4me3. Deposited by EZH2 of the polycomb group (PcG) and MLL2 of the trithorax group (TrxG) of proteins respectively, bivalent domains are the most widely studied mechanisms that render the gene 
inactive and active while, on the other hand, the presence of both marks keeps the gene poised for subsequent activation or suppression upon differentiation [1-6].

The relative distribution of these bivalent marks has been extensively uncovered, assigning them a crucial role in various mammalian developmental processes including cardiogenesis. Our group recently reported a vital role for EZH2 in the cardiac differentiation process wherein EZH2 is recruited by NR2F2 (cardiac marker) at the OCT4A promoter (pluripotency marker) for its repression in early cardiac differentiation stages by bringing about an H3K27me3 mark [7]. In addition to MLL2, there are other histone active methyltransferases recruited at the gene to activate transcription by methylating the target locus.

Histone methyltransferases have been shown to be guided at the genomic locations in specific cell types by directive roles of signaling pathways, histone variants, nucleosome remodeling, and transcription factors [8-11]), although the mechanistic and specificity details are still left to be uncovered. Cardiac differentiation has also been shown as an integration of genomic (transcription factors) and epigenetic (histone methyltransferases) information that collectively activates and deactivates the cardiac specific machinery. Epigenetic connection of cardiac formation was first put forward in 2005 when the key transcription factor GATA4 was shown to be coactivated by an acetylation mark brought about by histone acetyltransferase p300, thereby increasing its DNA binding ability and stability in cardiac myocytes differentiated from ES cells [12]. Activated GATA4 further binds to NKX2.5, another master cardiac transcription factor (TF) triggering cardiogenesis [13, 14]. Similarly, essential roles for histone demethylases like UTX and JMJD3 (H3K27me3 demethylases) have been reported to activate the cardiac genes during ES cell transition from pluripotency to cardiomyocytes [15-17]. NKX2.5 functions as an instrumental part of each of the differentiation stages like chamber formation, patterning of the conduction system, formation of the interventricular septum, defined expression of critical downstream genes, and terminal differentiation of the myocardium followed by their maturation into adult equivalents [18-22]. Understanding the signals and the modifications for the expression of cardiac transcription factors thus remains necessary to expose the mechanistic details for stepwise depiction of cardiac development.

DOT1L, unlike all other histone methyltransferases, represents the first crucial histone methyltransferase not containing an evolutionarily conserved catalytic domain called SET, referring to the Su(var)3-9, Enhancer of Zeste (E(Z)), and Trithorax (trx) domain [23]. DOT1L represents the only enzyme that activates its target by delivering dimethylation at lysine 79 of histone H3 [23-28]. Although DOT1L was initially identified for regulating heterochromatin formation [29, 30], accumulating literature now suggests its role in the regulation of gene activation [31-34]. An important area having DOT1L as an essential controller is that of cell cycle and DNA damage repair [35-37]. Involvement of DOT1L in in-vivo cardiac development and function has been shown by Nguyen and Zhang [38], wherein the group noted severe dilated cardiomyopathy in DOT1L knockout mice, which upon further study was rescued by ectopic expression of DOT1L, and that DOT1L is the possible target malfunctioning in dilated cardiomyopathy. The contribution of DOT1L in cardiac formation from undifferentiated mouse ES cells was reported recently [39]. The study successfully proved DOT1L expression on cardiac genes, which upon knocking down affects the expression of these genes delaying the cardiac differentiation. To conclude, DOT1L has an important role during cardiogenesis both in vivo and in vitro, and demands much more research efforts toward displaying its connection at the molecular and genetic levels as its deletion results in cardiac pathogenesis.

The present study was designed to understand whether DOT1L is crucial for the cardiac progenitor differentiation in vitro. Studies were carried out on the inhouse-derived hES cell line KIND1 along with a well-studied HES3 hES cell line. By performing chromatin immunoprecipitation (ChIP) followed by sequencing (ChIP-seq), we interrogated the hES cell-derived cardiac progenitors and beating CMs for the occupancy of an H3K79me2 mark on the specific cardiac genes. Dual immunofluorescence was performed to investigate whether cardiac specific transcription factor NKX2.5 is coexpressed with and activated by H3K79me2 methyltransferase DOT1L.

\section{Methods}

\section{Cell culture and differentiation}

KIND1 is an in-house derived hES cell line derived at our laboratory in Mumbai [40] and the HES3 cell line (WiCell Research Institute Inc.) was available from Dr Prabha Sampath's laboratory for the present study.

Undifferentiated feeder-free KIND1 hES cells were cultured in Stempro hES SFM medium (Invitrogen, Carlsbad, CA, USA) supplemented with $8 \mathrm{ng}$ of bFGF (Peprotech, NJ, USA) as described earlier [7], while the HES3 cell line was grown in $\operatorname{mTeSR}^{\mathrm{si}} 1$ medium (STEMCELL Technologies Inc., Canada) at $37{ }^{\circ} \mathrm{C}$ and $5 \% \mathrm{CO}_{2}$. For subjecting the confluent pluripotent KIND1 and HES3 hES cells to cardiac differentiation, they were transitioned from growth medium into RPMI 1640 containing 5\% B-27 and 1\% glutamax (basal medium), and the differentiation protocol was followed as reported by our group earlier [41]. In brief, cells were first exposed to basal medium supplemented with $100 \mathrm{ng} / \mathrm{ml}$ Activin A (Peprotech) and $5 \mathrm{ng} / \mathrm{ml}$ of bFGF (R\&D Systems, MN, 
USA) for $24 \mathrm{~h}$. This was followed by $15 \mathrm{ng} / \mathrm{ml} \mathrm{BMP4}$ (R\&D Systems) and $5 \mathrm{ng} / \mathrm{ml}$ bFGF (R\&D Systems) in basal medium for another 4 days. Finally, the cells were treated with WNT pathway blocker DKK1 (Peprotech) at $150 \mathrm{ng} / \mathrm{ml}$ concentration for the next 4 days. From day 9 onward, the cells were maintained in basal medium until day 20 wherein the media were changed on every alternate day.

\section{Quantitative polymerase chain reaction}

Total RNA was extracted using an RNeasy Mini Kit (Qiagen, Germany) and quantified using an ND1000 Spectrophotometer (NanoDrop Technologies, Inc., DE, USA). Then $500 \mathrm{ng}$ was subjected to reverse transcription for cDNA synthesis using SuperScript III Reverse Transcriptase (Thermo Fisher Scientific, MA, USA) as per the manufacturer's instructions using a 7900HT Fast RealTime PCR System (Thermo Fisher Scientific). Quantitative polymerase chain reaction (qPCR) was performed using SYBR Green chemistry (Thermo Fisher Scientific) on a 7900 HT Fast Real-Time PCR System. The program applied for amplification included $25{ }^{\circ} \mathrm{C}$ for $10 \mathrm{~min}, 50{ }^{\circ} \mathrm{C}$ for 50 min, and $85^{\circ} \mathrm{C}$ for $5 \mathrm{~min}$. The fold change was determined by the $2^{-\Delta \Delta \mathrm{Ct}}$ method and was expressed relative to that of an internal control, RPLPO. The expression level of each gene transcript is normalized to a value of 1.0 for undifferentiated cells. The error bars represent \pm standard error of the mean (SEM). All results are an average of at least three biological replicates. The primers used are presented in Table 1.

\section{ChIP sequencing}

ChIP was performed as per our recent report [7]. Briefly, about 1-2 million KIND1 and HES3 hES cells each harvested at days 0,12 , and 20 were subjected to

Table 1 Primer sequences

\begin{tabular}{ll}
\hline Gene & Primer sequence 5'-3' \\
\hline RPLPO & Forward: CAGATTGGCTACCCAACTGTT \\
& Reverse: GGGAAGGTGTAATCCGTCTCC \\
DOT1L & Forward: GAGACCTCCTTCGACCTGGT \\
& Reverse: CGACGCCATAGTGATGTTGC \\
MESP1 & Forward: CTCTGTTGGAGACCTGGATG \\
& Reverse: CCTGCTTGCCTCAAAGTG \\
MEF2C & Forward: CGAGATACCCACAACACACG \\
& Reverse: TTCGTTCCGGTGATCCTC \\
NKX2.5 & Forward: CCTCAACAGCTCCCTGACTCT \\
& Reverse: ATAATCGCCGCCACAAACTCTCC \\
ISL1 & Forward: TGATGAAGCAACTCCAGCAG \\
& Reverse: GGACTGGCTACCATGCTGT \\
CTNT & Forward: GGCAGCGGAAGAGGATGCTGAA \\
& Reverse: GAGGCACCAAGTGGGCATGAACGAC \\
\hline
\end{tabular}

formaldehyde crosslinking and sonication (Bioruptor; Cosmo Bio Co. Ltd, Japan). Sonicated protein-DNA complexes (200-500 bp) were precipitated with $10 \mu \mathrm{g}$ of anti-H3K79me2 antibody (Cell Signaling Technology, MA, USA) overnight at $4{ }^{\circ} \mathrm{C}$. Post thorough washing and elution, the ChIPped samples were subjected to standard DNA extraction protocol employing phenol:chloroform:isoamyl alcohol as per the manufacturer's instructions (Thermo Fisher Scientific). Extracted DNA samples were sent to the Genome Institute of Singapore (GIS), Singapore for sequencing on Illumina HiSeq2500 sequencer. The analysis of sequencing results obtained was performed at Sandor Life Sciences Pvt. Ltd (Hyderabad, India). The raw sequencing reads mapped with Humanhg19 were aligned using Bowtie (Galaxy tool) while peak calling was performed using MACS (Galaxy tool). Integrative Genome Viewer [42] was used for visualization of the resulting peaks.

\section{Dual-immunofluorescence}

The standard immunofluorescence protocol was followed to study expression of DOT1L and NKX2.5. Cells were grown in chamber slides followed by their differentiation and fixation with $4 \%$ paraformaldehyde (PFA) (Sigma-Aldrich, MO, USA) at days 0, 12, and 20 for 15 min followed by permeabilization with $0.3 \%$ triton X-100 (Sigma-Aldrich). Blocking was performed using phosphate buffer saline (PBS) containing 5\% BSA (Sigma Aldrich) plus 1\% normal goat serum (Bangalore Genei, Bangalore, India) for $60 \mathrm{~min}$ at room temperature. Cells were then incubated at $4{ }^{\circ} \mathrm{C}$ overnight with primary antibodies against DOT1L (1:200) (Abcam) and NKX2.5 (1:200) (R\&D Systems) diluted in blocking buffer. Later the cells were incubated in appropriate secondary antibodies (Thermo Fisher Scientific) diluted in blocking buffer for $2 \mathrm{~h}$ at room temperature. Representatives images were captured using a confocal microscope (Olympus FV1000).

\section{Knockdown experiments}

A small interfering RNA (siRNA)-based transfection technique for knocking down was employed to study the expression of DOT1L in both KIND1 and HES3 cells at days 0, 12, and 20. siRNAs for DOT1L along with a nontarget siRNA pool (control), with the following target sequences, were procured from GE Dharmacon ${ }^{\mathrm{TM}}$. DOT1L siRNAs (LQ014900-01-0010), (1) UCACUAUGGCGUCGAGAAA, (2) GCUAUGGAGAAUUACGUUU, (3) GCAGAAUCGUGU CCUCGAA, (4) AAGAGUGGAGGGAGCGAAU; and nontarget siRNA pool (D-001810-10-20), (1) UGGUUUACAUGUCGACUAA, (2) UGGUUUACAUGUUGUGUGA, (3) UGGUUUACAUGUUUUCUGA, (4) UGGUUUACAUGUUUUCCUA. Lipofectamine ${ }^{\mathrm{TM}}$ RNAiMAX Transfection Reagent (Thermo Fisher Scientific) was used to dilute the siRNAs for transfection as per the manufacturer's 
instructions. The pool of DOT1L siRNAs 1 and 3 gave the maximum knockdown at a concentration of $25 \mathrm{nM}$. Post incubation for $5 \mathrm{~min}$, siRNA DOT1L-lipid complex diluted in Opti-MEM $^{\text {tix }}$ Reduced Serum Medium (Thermo Fisher Scientific) was added to the cells. The medium was changed with Stempro hES SFM growth medium after $24 \mathrm{~h}$. Cells were harvested $72 \mathrm{~h}$ post knock down for subsequent analysis. For knocking down DOT1L in cardiac progenitors (day 12), transfection was performed at day 9 of differentiation protocol (described earlier), following which the progenitor cells were collected after $72 \mathrm{~h}$ (i.e., at day 12). Similarly, for knocking down the DOT1L at day 20 (cardiomyocyte stage), siRNA transfections were performed at day 17 of the cardiac-directed differentiation protocol.

\section{Results}

Differentiation of hES cells: KIND1 and HES3 cells display an identical cardiac differentiation pattern

Sequential addition of growth factors to undifferentiated KIND1 and HES3 cells led to a stepwise differentiation pattern into the cardiac lineage. Directed differentiation of pluripotent HES3 cells into the cardiac lineage was associated with distinct morphological changes ( see Additional file 1 for images taken at different time points of differentiation). Similar changes were observed when KIND1 cells were subjected to a similar differentiation protocol recently reported by our group [7]. Activation of the BMP and TGF- $\beta$ pathways with a high concentration of growth factor ligands like BMP4 and Activin
A resulted in upregulation of transcripts like GATA4 and KDR2 that represent the formation of early cardiac mesoderm. Following this, addition of DKK1 for inhibition of the WNT pathway further drove the differentiation toward the cardiac fate evident by expression of MESP1, $M E F 2 C$, ISL1, NKX2.5, and CTNT transcripts specific for cardiac mesoderm, cardiac progenitors, and beating cardiomyocytes (observed only in KIND1 cells). Depending upon the gene expression pattern, we harvested the cells at days 0 , 12, and 20 during differentiation of both KIND1 and HES3 cells, which depict undifferentiated pluripotent hES cells, cardiac progenitors, and beating cardiomyocytes for carrying out further studies. The corresponding changes in specific transcripts that were expected to change during differentiation and protein expression of CTNT and NKX2.5 in differentiating HES3 cells are presented in Additional files 2 and 3. These results are also similar to earlier published data using KIND1 cells [7].

Interestingly with these results, we for the first time report the typical cardiac differentiation pattern following a 20-day directed differentiation protocol in the HES3 cell line. In addition, a similar morphology observed in both cell lines at each stage during cardiac differentiation, further validating our protocol as well as the pattern of cardiac differentiation from hES cells. Beating cardiomyocytes were observed only in KIND1 cells perhaps because of intrinsic differences between the two cell lines. KIND1 cells were derived on human feeder fibroblasts whereas HES3 cells were derived initially on mouse embryonic fibroblast support.

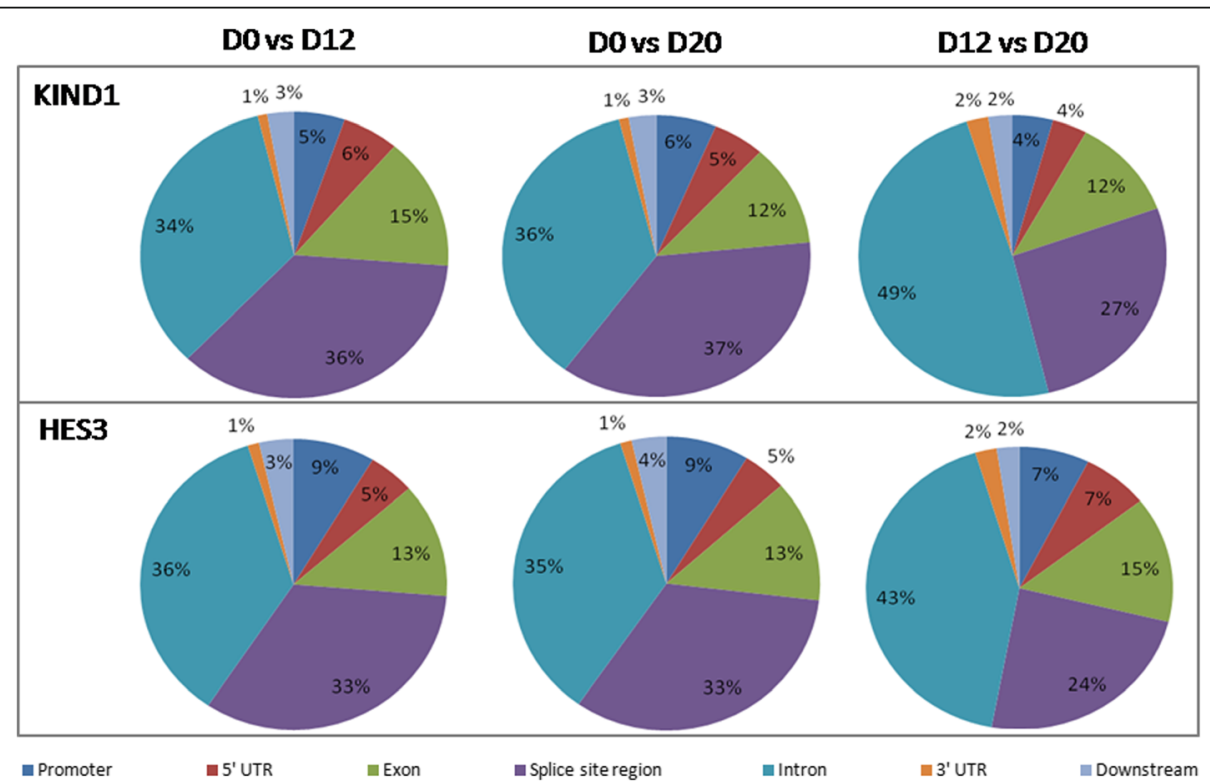

Fig. 1 H3K79me2 peak deposition on genomic regions in (a) KIND1 and (b) HES3 cells. Pie charts represent disposition of H3K79me2 methyl mark over genomic regions, represented as percentage of peaks of KIND1 and HES3 cells during their directed differentiation into cardiac lineage from D0 to D12, D0 to D20, and D12 to D20. D day, UTR untranslated region 
ChIP-seq: H3K79me2 targets cardiac lineage genes during differentiation of KIND1 and HES3 cells

We first sought to understand the occupancy of H3K79me2 modification onto the genomic regions in undifferentiated as well as differentiating hES cells toward the cardiac lineage. Chromatin immunoprecipitation followed by sequencing (ChIP-seq) visualized an interesting expression pattern of an H3K79me2 methyl mark onto the expressed genes. The enrichment of H3K79me2 mark appeared upstream of exons including the promoters and the 5'UTR regions of genes, with a significant proportion of peaks occupying downstream regions of the transcription start site (TSS) as per the known localization pattern of this mark (Fig. 1). Analyzing the status of this dimethyl mark at day 0, transcripts like POU5F1, NANOG, and SOX2 representing the pluripotent hES cells accumulated H3K79me2 peaks toward the downstream of TSS and disappeared at both the day 12 and day 20 stage of cardiac differentiation (Fig. 2). This highlights the possible role of an H3K79me2 methyl mark in their activation in an undifferentiated state. Further analyzing the cells at days 12 and 20, the active genes

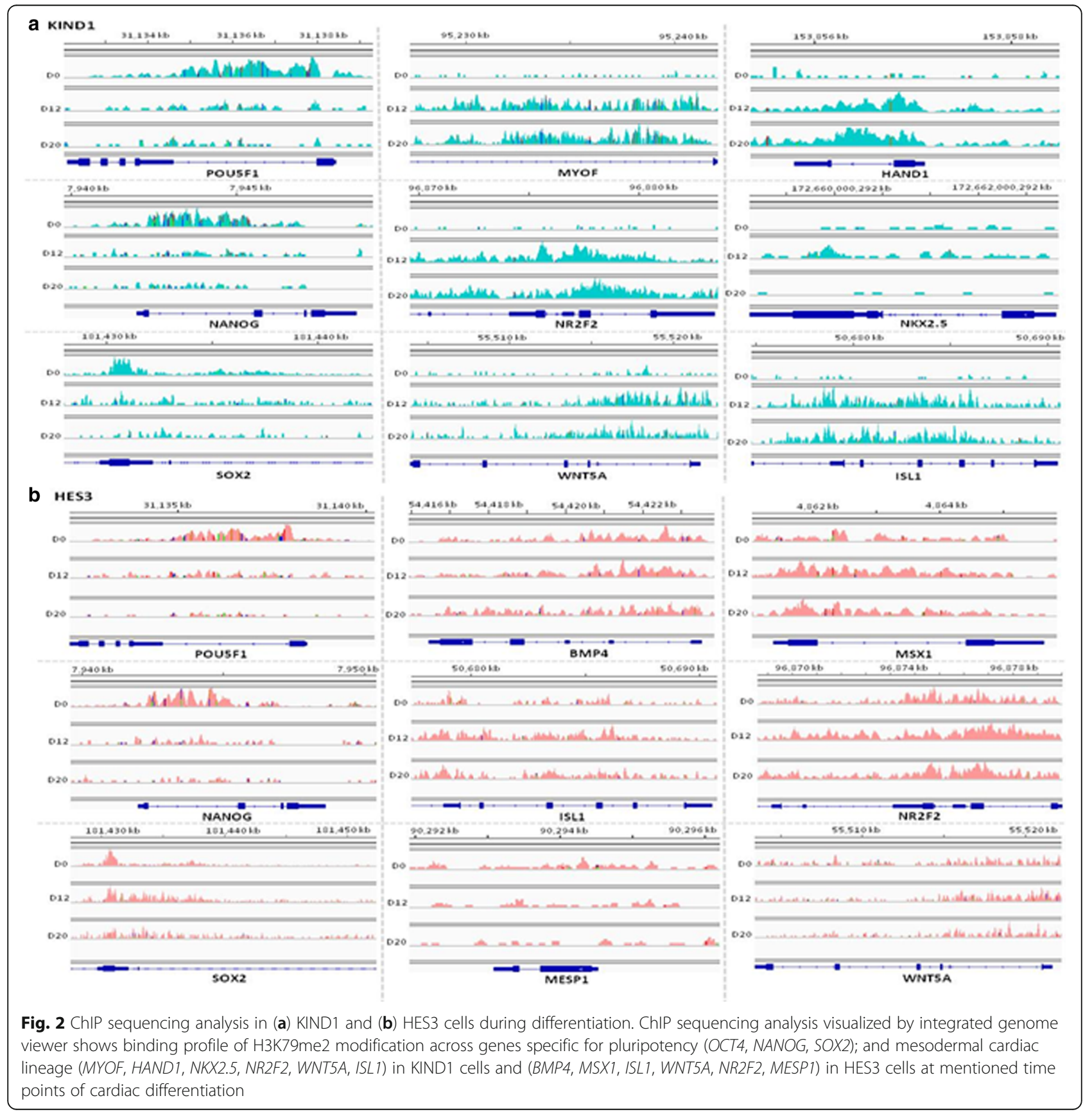


comprised key transcripts representing the cardiac lineage like BMP4, GATA4, KDR2, ISL1, MEF2C, MSX1, MYH6, MYL2, NKX2.5, NR2F2, T, TNNT2, WNT5A, HAND1, and $M Y O F$ (Fig. 2a, b). On extending our analysis, significant signals of H3K79me2 peaks were noted at the intron, 3' UTR, and splice site regions of genes including $H N F 4 A$, LEFTY1, NOGGIN, NQO1, OTX2, SOX7, and NPTX2 (results shown for both KIND-1 and HES3 cells in Additional file 4). Expression patterns in both hES cell lines employed in the present study displayed high similarity, implying the crucial collaboration of H3K79me2 modification with the cardiac gene expression machinery. With respect to the various findings describing its roles in transcriptional activation or for the derepression of heterochromatin locally [31, 33, 43-45], DOT1L is also known as the critical regulator of the cell cycle process wherein enriched expression of DOT1L is found during the $\mathrm{G} 2 / \mathrm{M}$ phase $[36,46]$.

On the other hand, deficiency of DOT1L results in cell cycle progression defects and aneuploidy in differentiating ES cells [35, 47]. In support of this, we in our present analysis also noted the significant peaks at $P C N A$, the gene required for DNA replication known as the marker of cell proliferation of cardiac muscle cells [48]. Additional cell cycle regulators containing an H3K79me2 mark include BUB1 and BRCA1 along with $E 2 F 5$, an antiapoptotic factor in cardiomyocytes. These analyses, besides confirming the differentiation of KIND1 and HES3 hES cells into the cardiac lineage, also reveal the necessary involvement of dimethylation of H3K79 as a putative activation mark for induction of gene activation during cardiogenesis in vitro.

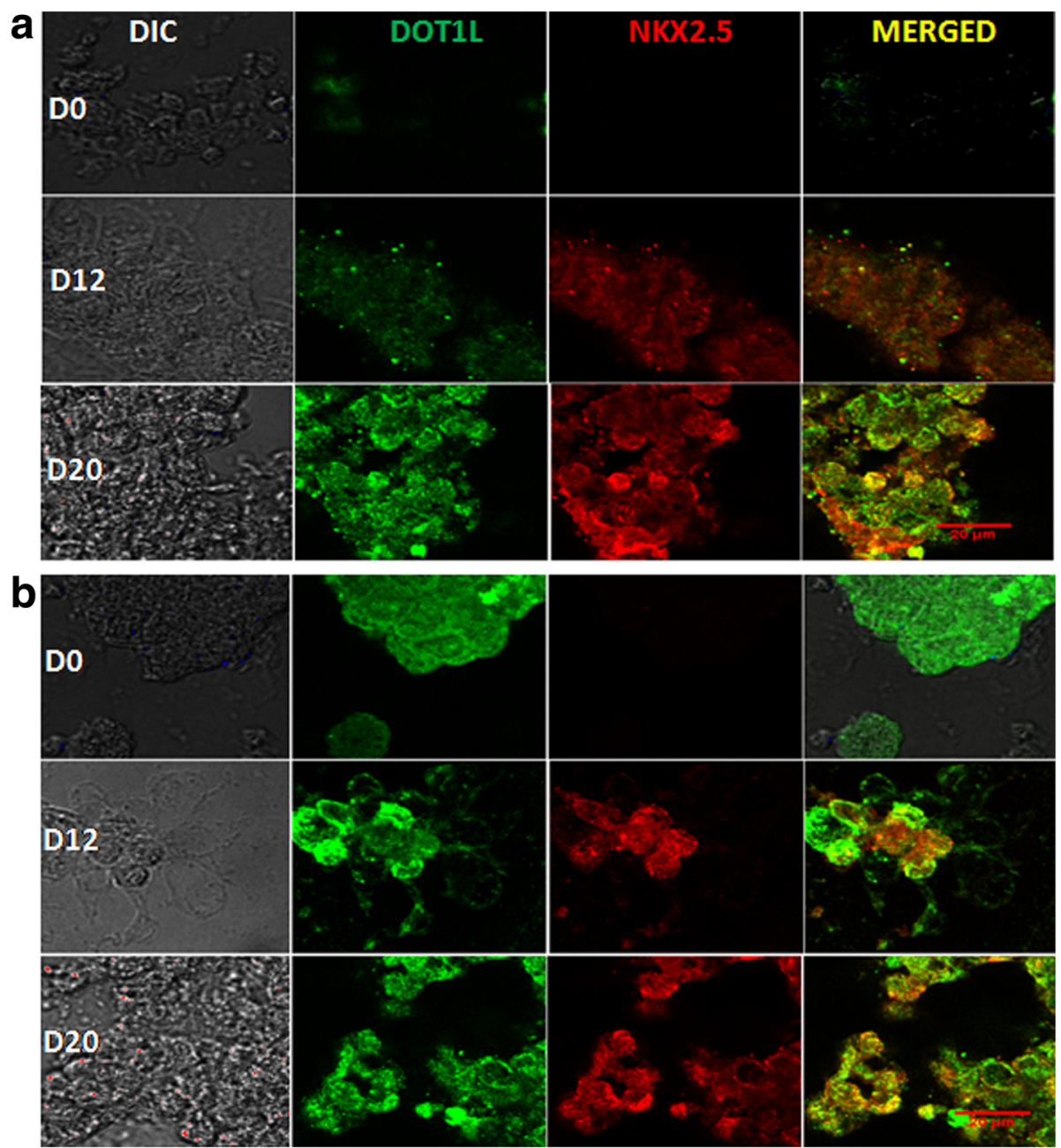

Fig. 3 Coexpression of DOT1L and NKX2.5 in (a) KIND1 and (b) HES3 cells during differentiation. Dual immunofluorescence revealed coexpression of histone modifier DOT1L (green, nuclear) along with the master cardiac transcription factor NKX2.5 (red, nuclear) on days 12 and 20 during cardiac directed differentiation of KIND1 and HES3. These markers not expressed in undifferentiated cells (D0) of both KIND1 and HES3 cells. Scale bar: 20 4m. D day, DIC differential interference contrast 
Dual immunofluorescence: coexpression of DOT1L and NKX2.5 in cardiac progenitors

NKX2.5 is an essential marker for cardiac progenitors during in-vivo embryonic development as well as in-vitro differentiation of pluripotent cells. In continuation of the observation that an H3K79me2 mark occurs on NKX2.5, we were then interested to see whether H3K79me2 methyltransferase DOT1L is involved in activation of the NKX2.5 gene by delivering an H3K79me2 mark leading to its expression that is essential for the downstream cardiogenesis. This coappearance of DOT1L and NKX2.5 was investigated by dual immunofluorescence performed at days 0,12 , and 20. Figure 3 clearly reveals the significant number of areas coexpressing DOT1L and cardiac marker NKX2.5 at the progenitor (day 12) and the beating cardiomyocyte (day 20) stages obtained from KIND1 and HES3 cells. On the other hand, no colocalization was observed for DOT1L and NKX2.5 at the pluripotent (day 0) stage of the cells. These obvious results further indicate that
DOT1L might be coactivating the key cardiac transcript NKX2.5 by bringing about an H3K79me2 activation mark.

In support of these results, Dystrophin $(D M D)$ expression was upregulated in cardiac progenitors and beating cardiomyocytes compared to undifferentiated KIND1 cells (Additional file 5). ChIP sequencing analysis also revealed significant peaks representing the H3K79me2 occupancy at the $D M D$ gene in differentiated cardiac cells obtained from both KIND1 and HES3 cells (see Additional file 6). In their mechanistic study, Nguyen and Zhang [38] revealed that DOT1L functions in cardiomyocytes through regulating $D M D$ transcription and that $D M D$ is a direct target of DOT1L. The present study clearly reports a correlated expression of $D M D$ and DOT1L-mediated H3K79me2 methylation in cardiac cells. The results are in compliance with published studies and report the expression of $D M D$ in cardiac cells differentiated from hES cells for the first time, further implying the active involvement of DOT1L during cardiac differentiation.
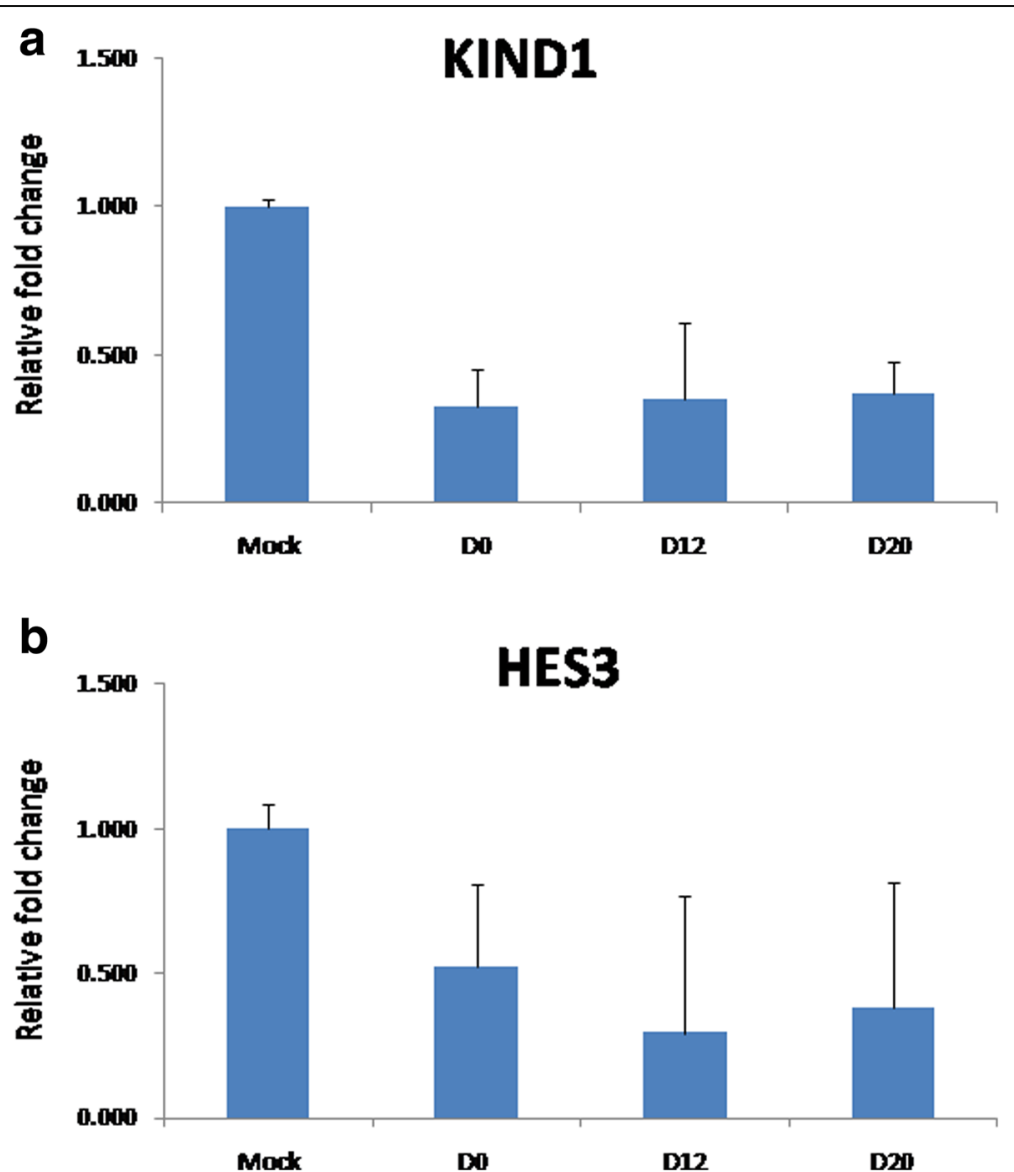

Fig. 4 DOT1L expression in (a) KIND1 and (b) HES3 cells after DOT1L siRNA treatment. About 70-75\% DOT1L knockdown was achieved by DOT1L siRNA treatment in both KIND1 and HES3 cell lines compared to mock control. Error bars represent \pm SEM. Knockdown is a result of three independent experiments. D day 


\section{Knockdown studies: DOT1L deficiency leads to compromised cardiogenesis from KIND1 and HES3 cells} Since DOT1L and its methylation mark H3K79me2 were found to be expressed along with NKX2.5, we then planned to explore whether DOT1L is crucially required in both regulating the pluripotent state as well as for obtaining cardiac progenitors. For this, we moved ahead with knocking down the DOT1L expression in both KIND1 and HES3 cells followed by their inspection both at pluripotent as well as during cardiac differentiation stages. In addition to comparing the gene expression status in DOT1L knocked down hES cells with that of wild-type hES cells, both cell lines were simultaneously transfected with nontarget siRNA control. With the achievement of about $70 \%$ and $75 \%$ of DOT1L knockdown in KIND1 and HES3 cells (Fig. 4), we first monitored its effect upon proliferation and maintenance of hES cells in their pluripotent state. Interestingly, post knock down both KIND1 and HES3 cells were morphologically indistinguishable when compared to their wild-type or control counterparts (Fig. 5). Confirming this at the transcript by qPCR, the expression of key pluripotent marker OCT4 was seen to be unchanged in wild-type, negative control, and post-DOT1L knockdown hES cells at day 0 (undifferentiated) (Fig. 6). This is consistent with a couple of earlier reports stating that DOT1L does not inhibit the pluripotency of ES cells and that they retain the expression of pluripotent markers as evident at both transcript and protein levels [35, 39]. Extending ahead from the pluripotent state, we then worked further to examine the potential of both cell lines post knock down to differentiate and give rise to cardiac progenitors using the same differentiation protocol as described earlier. We first looked for the shift from the typical morphology that we observed during cardiac differentiation from KIND1 and HES3 cells as described. DOT1L knockdown severely impaired the normal differentiation of hES cell lines into cardiac progenitors,

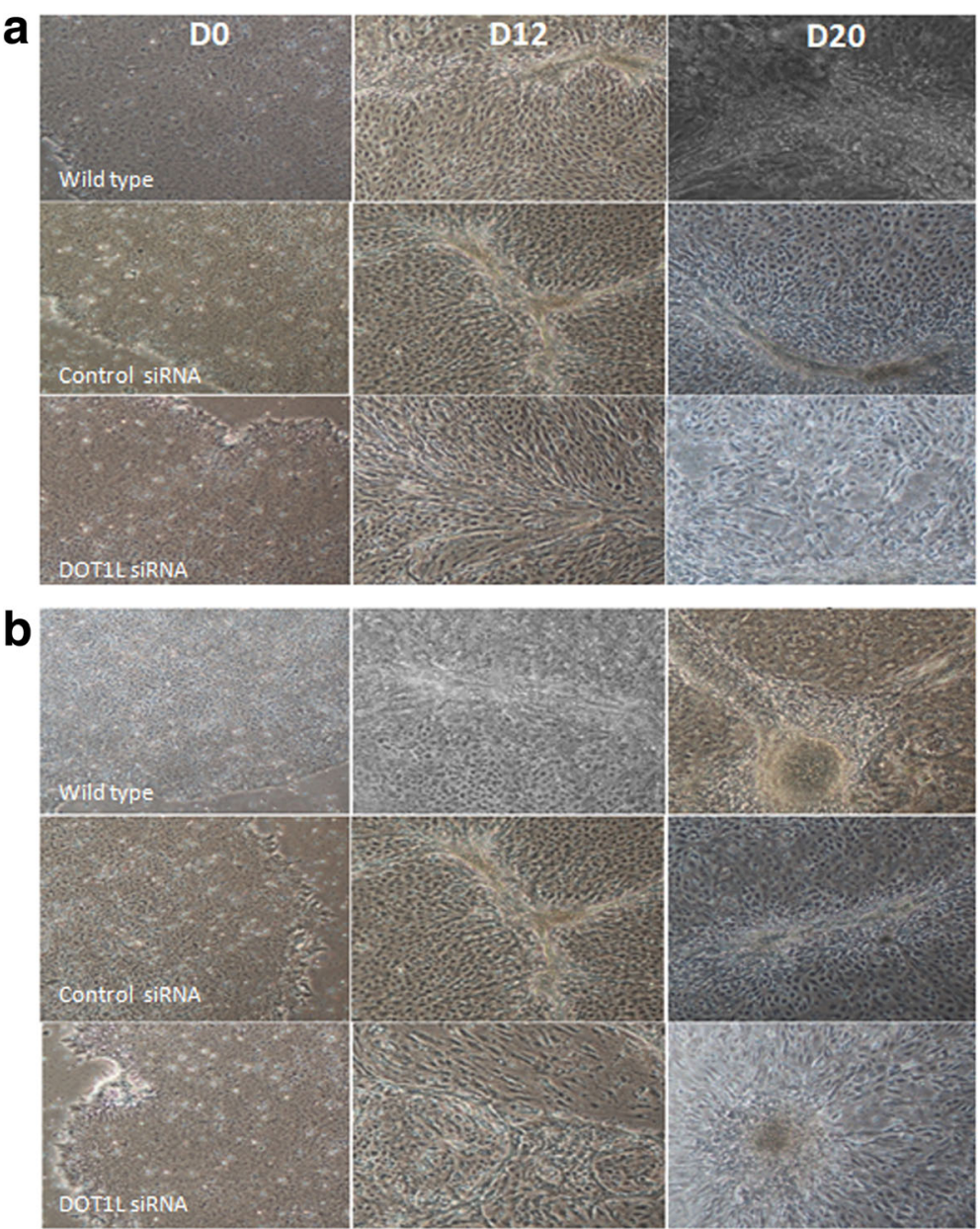

Fig. 5 Effect of DOT1L knockdown on (a) KIND1 and (b) HES3 cell morphology on different days of differentiation. Both KIND1 and HES3 cells displayed mesenchymal morphology in their wild-type and nontarget siRNA-treated state characteristic of the mesodermal to cardiac differentiation as compared to the impaired cardiac differentiation pattern noted post DOT1L knockdown. Magnification 10X. D day 

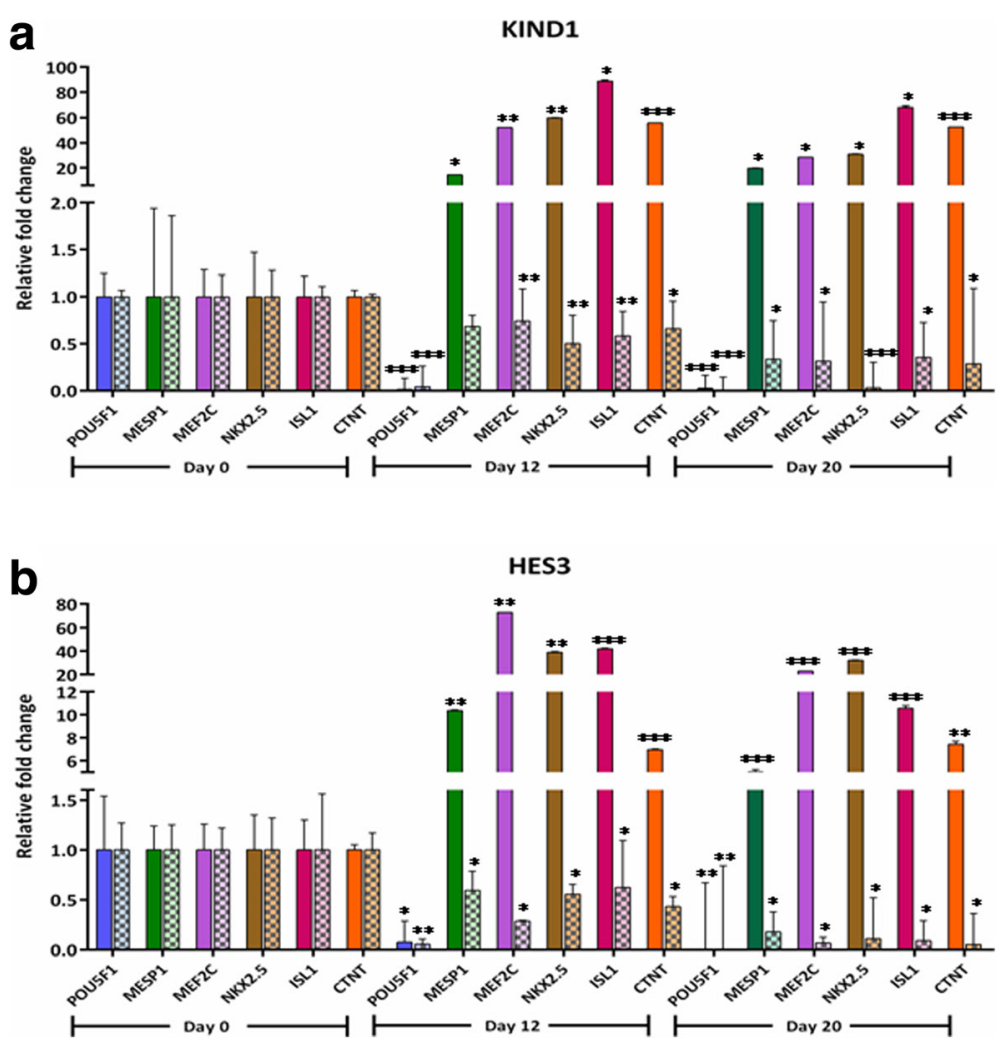

Fig. 6 Effect of DOT1L knockdown on pluripotent and cardiac specific transcripts by qRT-PCR analysis in (a) KIND1 and (b) HES3 cells. Relative expression for pluripotency (OCT4) and cardiac specific (MESP1, MEF2C, NKX2.5, ISL1, CTNT) transcripts during differentiation of KIND1 and HES3 cells, normalized to internal control RPLPO and presented as fold change of expression. Nonpatterned bars represent expression levels in cells with nontarget siRNA while patterned bars represent expression in cells after DOT1L siRNA treatment. Error bars represent \pm SEM of three independent knockdown experiments. Statistical significance: ${ }^{*} p<0.5,{ }^{* *} p<0.01,{ }^{* *} p<0.001$

as evidenced by the depleted morphological pattern of cells at day 12 obtained post DOT1L knock down; as compared to that seen in cells containing no target siRNA pool or the wild-type KIND1 and HES3 cells (Fig. 5).

Further qPCR analysis was carried out to understand the status of $N K X 2.5$ expression at the transcript level (Fig. 6). While the expression of NKX2.5 in progenitor cells containing no target siRNA was comparable to that obtained from wild-type cells, the levels of NKX2.5 expression in progenitors derived from cells deficient for DOT1L were drastically affected at both progenitor (day 12) and cardiomyocyte (day 20) stages when compared with control or wild-type cells at the respective stages. About $60 \%$ and $80 \%$ of reduced NKX2.5 levels were denoted at day 12 and day 20 respectively, differentiated from both KIND1 and HES3 cells. This indicates that depletion of DOT1L in hES cells resulted in significantly reduced NKX2.5 expression and thus cardiac progenitor formation. To further investigate whether DOT1L is crucial for the downstream targets of $N K X 2.5$, we checked for the expression of other cardiac representative genes like MESP1, MEF2C, ISL1, and CTNT in progenitors and cardiomyocytes obtained from KIND1 and HES3 cells. An intensely diminished gene expression level of these markers was noted at day 12 that was further reduced at day 20 . These observations extend the effects of depletion of DOT1L according to which not only NKX2.5 but also the downstream transcriptional targets of NKX2.5 are influenced leading to much less or no cardiomyocyte formation in vitro. To further confirm these results, we performed dual immunofluorescence to study the coexpression of NKX2.5 and DOT1L in cardiac progenitors deficient for DOT1L (Figs. 7 and 8). While we observed considerable areas, displaying their colocalization in control and wild-type hES cells, there was very little or no expression of either markers in the cardiac progenitors containing siDOT1L. These results further help establish the fact that DOT1L has a decisive participation in early incidents of cardiac differentiation from hES cells.

\section{Discussion}

In the present study, we aimed to understand the importance of active histone modifier DOT1L during cardiac differentiation in vitro on hES cells. In-housederived KIND1 and HES3 cell lines were used for the study. The ability of KIND1 cells to differentiate into 

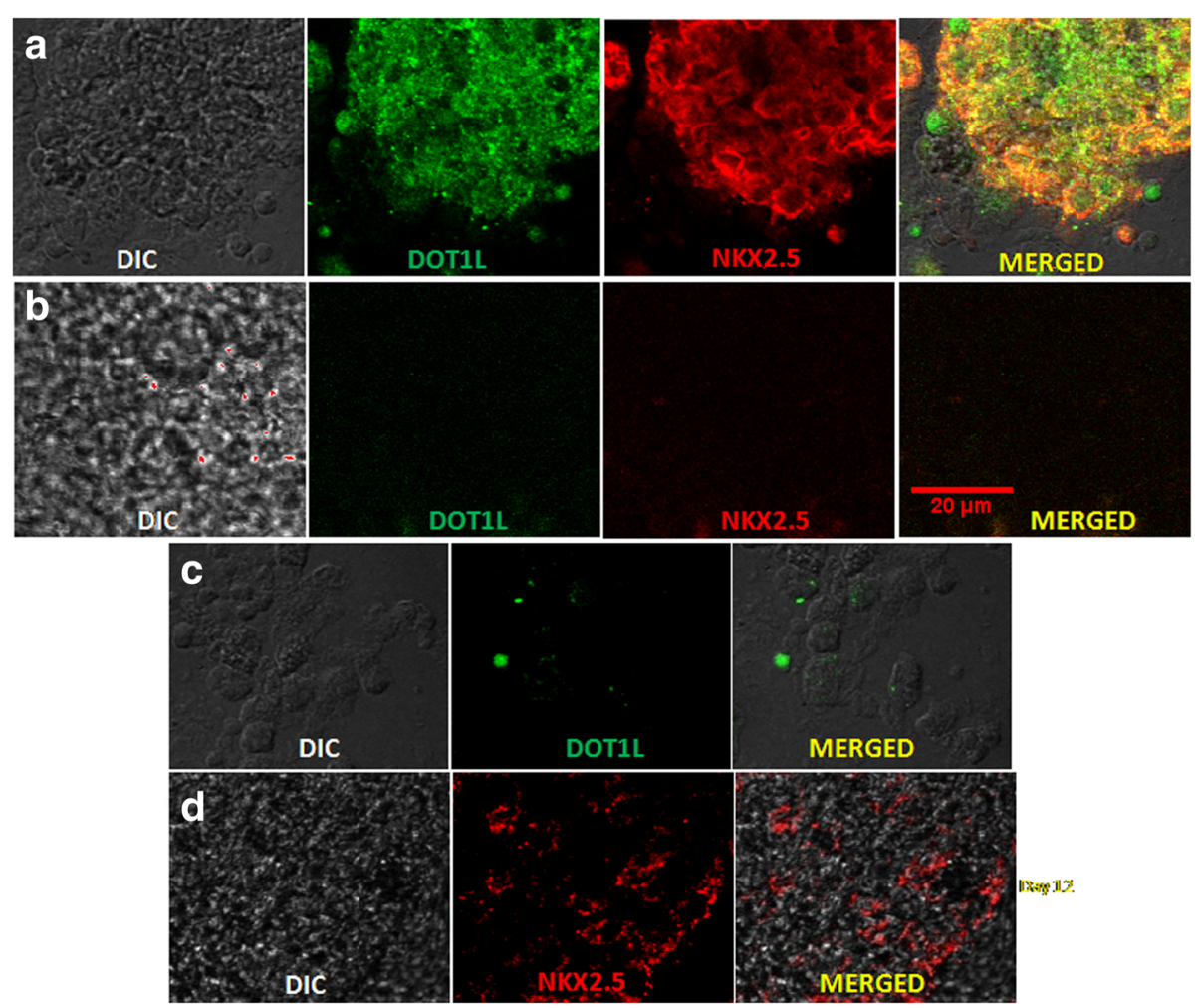

Fig. 7 Effect of DOT1L knockdown on coexpression of DOT1L and NKX2.5 during KIND1 differentiation into the cardiac lineage. Immunostaining for DOT1L and NKX2.5 in KIND1 cells during cardiac differentiation. a Coexpression of DOT1L and NKX2.5 in nontarget siRNA-treated controls at day 12. b Coexpression of DOT1L and NKX2.5 in siRNA-treated cells on day 12. $\mathbf{c}$. d Expression of DOT1L and NKX2.5 in siRNA-treated HES3 cells at days 0 and 12 respectively. Scale bar: $20 \mu \mathrm{m}$. DIC differential interference contrast

cardiac progenitors and beating cardiomyocytes has been published previously [7, 41]; however, the present study provides the first results on cardiac differentiation of HES3 cells using a directed differentiation protocol. ChIP sequencing was performed to look for the DOT1L specific mark H3K79me2 in differentiating KIND1 and HES3 cells. As per the known localization of H3K79me2 modification, significant peaks were noted at the downstream regions of pluripotent genes like OCT4, SOX2 and NANOG, whereas genes like GATA4, HAND1, NR2F2, NKX2.5, MESP1, ISL1, and WNT5A harbored the H3K79me2 peaks as the cells underwent differentiation into cardiac progenitor and cardiomyocyte stages. ChIP sequencing analysis also revealed the significant peaks of H3K79me2 on the DMD gene at days 12 and 20 in both KIND1 and HES3 cells, suggesting its direct upregulation by DOT1L during cardiac differentiation. Employing dual immunofluorescence, colocalization of DOT1L was studied with the master cardiac transcription factor NKX2.5. While NKX2.5 was not expressed in the pluripotent stage, substantial areas showing coexpression of DOT1L and NKX2.5 were located in cardiac progenitors upon differentiation from both KIND1 and
HES3 cells. Moreover, expression of $D M D$ was also increased as undifferentiated KIND1 hES cells differentiated into cardiac progenitors and cardiomyocytes, and correlated with the DOT1L expression and H3K79me2 methylation. Further studies were undertaken to study the effects of loss of DOT1L on differentiating KIND1 and HES3 cells. A 70-75\% knock down of DOT1L was obtained in hES cells using siRNA technology. Remarkably, DOT1L knockdown did not show any deleterious effects on the pluripotency of hES cells maintaining their typical morphology as well as the expression of pluripotency gene OCT4; however, deficiency of DOT1L severely attenuated the cardiac differentiation pattern in KIND1 cells as well as HES3 cells. Furthermore, transcription factor $N K X 2.5$ and its downstream targets like GATA4, TBX5, and ISL1 were found to be critically downregulated at cardiac progenitor and cardiomyocyte stages when DOT1L was knocked down. This was further confirmed when cells lacking DOT1L did not show coexpression of NKX2.5 and DOT1L by immunofluorescence. We report the possible involvement of histone activating methyltransferase DOT1L during cardiac differentiation of hES cells. Such studies, besides helping to 

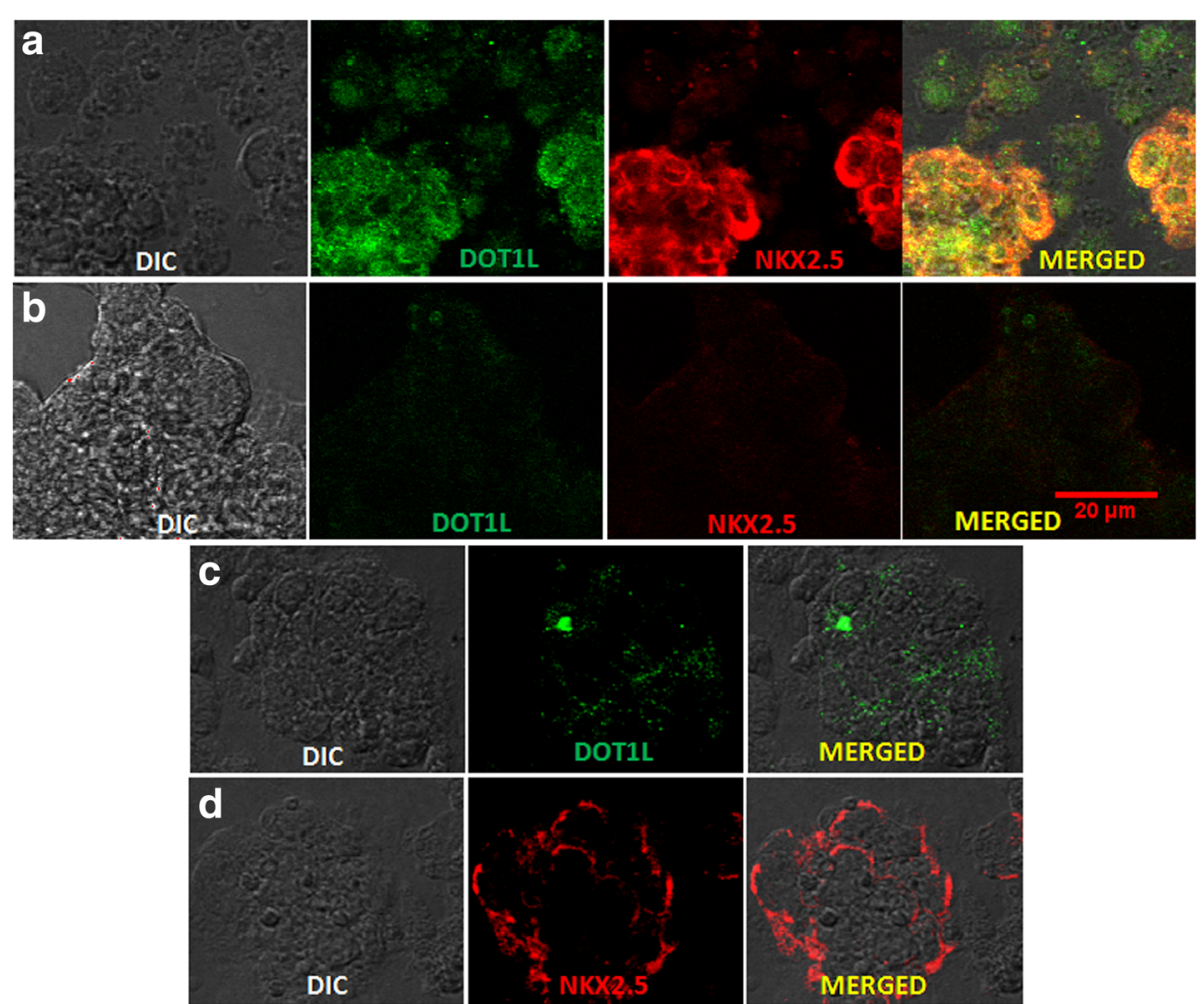

Fig. 8 Effect of DOT1L knockdown on coexpression of DOT1L and NKX2.5 during HES3 cell differentiation into the cardiac lineage. Immunostaining for DOT1L and NKX2.5 in HES3 cells during cardiac differentiation. a Coexpression of DOT1L and NKX2.5 in nontarget siRNA-treated controls at day 12. b Coexpression of DOT1L and NKX2.5 in DOT1L siRNA-treated HES3 cells at days 12. $\mathbf{c}$, d Expression of DOT1L and NKX2.5 in siRNA-treated HES3 cells at days 0 and 12 respectively. Scale bar: $20 \mu \mathrm{m}$. DIC differential interference contrast

improve the efficiency of hES cell differentiation, would further aid in better understanding the early events underlying cardiac differentiation in vitro.

High levels of active methylation marks occur upon the euchromatin or the open chromatin that is accessible to the transcription machinery. Cardiac cell fate also depends upon its specific and timely gene expression mechanisms that in turn are largely regulated by active epigenetic modifications like H3K4me3, H3K36me3, and $\mathrm{H} 3 \mathrm{~K} 79 \mathrm{me}$. H3K4me3 is indispensable in cardiac developmental genes, evidenced by exome sequencing to identify the underlying mutations in CHD patients. This includes genes like GATA4, NKX2.5, and TBX5 read with mutated H3K4 methylation [49]. Crucial involvement of MLL2 is also visualized in differentiating mES cells that directly controls cardiac specific genes by promoting H3K4me3 deposition [50]. H3K36me3 represents a second crucial active methylation mark found to be enriched upon NKX2.5. Interaction of H3K36me3 methyltransferase WHSC1 and NKX2.5 has remarkably shown the regulation of another set of genes like PDGFRA and NPPA. In support of this, WHSC1 mutant hearts resulted in cardiac developmental defects consistent with NKX2.5 heterozygous mutants, further confirming their functional link [51]. Results of the present study show the key role of the transcription activating mark represented by H3K79me2 deposited onto the actively transcribing genes by DOT1L. These findings suggest the involvement of multiple histone activating methyltransferases for the activation of a gene in cardiac differentiation. However, what further remains to be revealed is whether there exists a collaborative effort by these epigenetic modifiers and also the effects of loss of one enzyme on the functions of another epigenetic modifier.

NKX2.5 represents a critical cardiac developmental factor that essentially directs the multiple downstream genes required for cardiac morphogenesis and maturation. This is supported by the conduction and contraction defects leading to premature death upon its deletion in vivo [52-54]. NKX2.5 mutations also predispose the patients to cardiac developmental disorder termed dilated cardiomyopathy (DCM). Involvement of NKX2.5 in processes like cardiomyocyte specification and their homeostasis, development of the conduction system and cardiac muscle cells, as well as septation and nodal formation makes it a central participant in the genetic model for DCM [55-58]. Several reports also implicate epigenetic factors as causal events of DCM. Nguyen and 
Zhang [38] showed the significant role of DOT1L in the pathogenesis of DCM and that cardiac-specific conditional knockout for DOT1L in mice was lethal in nature. This study also reported mechanistic details showing DMD as the key target mediating DOT1L function in cardiac cells. Our results are in agreement with these published reports and provide a possible mechanism involving DOT1L during cardiogenesis leading to various pathologies. This further opens up the question of whether the genetic cause of DCM with respect to NKX2.5 is due to failure of its activation by DOT1L and hence its loss of function.

Our study opens up a number of areas that further need to be explored in order to design a DOT1Lcentered gene expression model. Similarly, the other gene activating factors might also be involved along with DOT1L since DOT1L is known to function in coordination with MLL2 for maintenance of gene expression in leukemia [59]. Crosstalk among histone methyltransferases also requires further investigation. On the other hand, understanding the effects of overexpression of DOT1L during in-vitro cardiac differentiation might also uncover newer layers of regulation of cardiac gene expression.

\section{Conclusions}

The present study, besides uncovering the contribution of DOT1L in cardiac differentiation from hES cells, puts forward a wide range of exciting possibilities that would aid in enhancing the efficiency of cardiac differentiation from hES cells as well as their clinical applications. However, further studies showing altered occupancy of H3K79me2 mark post DOT1L knock down as well as demonstrating direct binding of DOT1L to NKX2.5 in a pure population of cardiomyocytes need to be studied in order to further substantiate our findings.

\section{Additional files}

Additional file 1: Brightfield images of HES3 hES cells during directed differentiation into cardiac lineage. Differentiation results in distinct morphological changes leading to increased compaction among the cells as differentiation proceeds from day 0 to day 20. Similar changes observed when KIND1 cells were differentiated into cardiac cells as described earlier [43]. Magnification 10x. (PDF 554 kb)

Additional file 2: Characterization of cardiac differentiation of HES3 cells by quantitative real-time PCR (qRT-PCR). Expression of transcripts representing pluripotency (OCT4), cardiac mesoderm (MESP1), cardiac progenitors (NKX2.5, MEF2C), and cardiomyocytes (CTNT) at days 0, 12, and 20 during 20 days of cardiac differentiation. Note OCT-4 expression in undifferentiated cells is downregulated as the cells initiate differentiation. Early cardiac markers detected on day 12 and mature markers upregulated on day 20. Similar changes in transcripts expression observed when KIND1 cells were differentiated into cardiac cells as described earlier [43]. Error bars represent \pm SEM. (PDF $410 \mathrm{~kb}$ )

Additional file 3: Characterization of cardiac differentiation of HES3 cells by immunofluorescence studies. Expression of NKX2.5 (A) and CTNT (B) on days 12 and 20 observed by immunofluorescence. (A) Distinct nuclear expression of NKX2.5 observed and (B) CTNT cell surface expression. Similar changes observed when KIND1 cells were differentiated into cardiac cells as described earlier [43]. Counterstaining using DAPI. Magnifications 20x. (PDF $450 \mathrm{~kb}$ )

Additional file 4: ChIP sequencing in KIND1 and HES3 cells during cardiac differentiation visualized by Integrated Genome Viewer shows binding profile of H3K79me2 modification across genes HNF4A, LEFTY1, NOGGIN, NQO1, OTX2, and NPTX2 in KIND1 (green) and HES3 (red) cells at days 0,12 , and 20 of cardiac differentiation. (PDF $548 \mathrm{~kb}$ )

Additional file 5: Dystrophin gene expression during cardiac differentiation of KIND1 hES cells on days 0, 12, and 20 during cardiac differentiation of KIND1 hES cell line. Expression of Dystrophin increased in cardiac progenitors and cardiomyocytes compared to undifferentiated KIND1 cells. Results in agreement with earlier reports in DOT1L conditional knockout mice heart concluding Dystrophin as a direct target of DOT1L [35]. Error bars represent

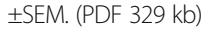

Additional file 6: ChIP sequencing of occupancy of H3K79me2 on DMD gene during cardiac differentiation of KIND1 and HES3 cells showing occupancy of H3K79me2 methylation mark brought about by DOT1L on DMD gene during cardiac differentiation. Results clearly show significant peaks representing the DOT1L specific methylation mark on days 12 and 20 as compared to day 0 suggestive of its activation by DOT1L during cardiac differentiation in vitro. (PDF $614 \mathrm{~kb}$ )

\section{Abbreviations}

bFGF: Basic fibroblast growth factor; CHD: Chronic heart disease; ChIP: Chromatin immunoprecipitation; hES: Human embryonic stem; PBS: Phosphate buffered saline; PCG: Polycomb group; PCR: Polymerase chain reaction; PSC: Pluripotent stem cell; TrxG: Trithorax group

\section{Acknowledgements}

The authors thank the sequencing facility of the Genome Institute of Singapore for sequencing services, Sandor Life Sciences for sequencing data analysis, the Institute of Medical Biology (IMB) Microscopy Unit for confocal studies, Paul for assistance with providing HES3 cell cultures, Colin Stewart for cell culture facility, and Wai Kay Kok and Rafidah for their technical and experimental inputs. Special thanks to Gopinath Sundaram for guidance in confocal and knockdown studies.

\section{Funding}

The Council of Scientific \& Industrial Research (CSIR), Government of India, New Delhi and core funding by the Indian Council of Medical Research, Government of India, New Delhi supported this study. The authors also acknowledge the Department of Science and Technology-INSPIRE (DSTINSPIRE), Government of India for providing an INSPIRE fellowship to VP.

\section{Availability of data and materials}

The ChIP sequencing raw datasets generated during the current study are available in the NCBI Sequence Read Archive (SRA) repository under accession number SRP115341.

\section{Authors' contributions}

VP was involved in study design, carrying out experiments, performing data analysis and interpretation, and manuscript preparation. DB was involved in obtaining funds, data interpretation, and manuscript preparation. VT was involved in experimental design and discussions. MB was involved in carrying out experiments. PS was involved in experimental and scientific inputs. All authors read and approved the submitted version of the manuscript.

\section{Authors' information}

Not applicable.

\section{Ethics approval and consent to participate}

Not applicable.

\section{Consent for publication}

All authors read and approved the final version of the manuscript for submission. ICMR-NIRRH Accession number RA/502/07-2017. 


\section{Competing interests}

The authors declare that they have no competing interests.

\section{Publisher's Note}

Springer Nature remains neutral with regard to jurisdictional claims in published maps and institutional affiliations.

\section{Author details}

${ }^{1}$ Stem Cell Biology Department, ICMR-National Institute for Research in Reproductive Health, J.M. Street, Parel, Mumbai, Maharashtra 400 012, India. 2Division of Biological \& Life Sciences, School of Arts \& Sciences, Ahmedabad University, Ahmedabad 380009, India. ${ }^{3}$ Genome and Gene Expression Data Analysis Division, A* Star-Bioinformatics Institute, Singapore 138671, Singapore. ${ }^{4}$ Division of Translational Control of Disease, $A^{*}$ Star-Institute of Medical Biology, Singapore 138648, Singapore.

Received: 27 September 2017 Revised: 12 February 2018 Accepted: 20 February 2018 Published online: 10 April 2018

\section{References}

1. Azuara V, Perry P, Sauer S, Spivakov M, Jorgensen HF, John RM, Gouti M, Casanova M, Warnes G, Merkenschlager M, Fisher AG. Chromatin signatures of pluripotent cell lines. Nat Cell Biol. 2006:8:532-8.

2. Bernstein BE, Mikkelsen TS, Xie X, Kamal M, Huebert DJ, Cuff J, Fry B, Meissner A, Wernig M, Plath K, Jaenisch R, Wagschal A, Feil R, Schreiber SL, Lander ES. A bivalent chromatin structure marks key developmental genes in embryonic stem cells. Cell. 2006;125:315-26.

3. Mikkelsen TS, Ku M, Jaffe DB, Issac B, Lieberman E, Giannoukos G, Alvarez P, Brockman W, Kim TK, Koche RP, Lee W, Mendenhall E, O'Donovan A, Presser A, Russ C, Xie X, Meissner A, Wernig M, Jaenisch R, Nusbaum C, Lander ES, Bernstein BE. Genome-wide maps of chromatin state in pluripotent and lineage-committed cells. Nature. 2007:448:553-60.

4. Pan G, Tian S, Nie J, Yang C, Ruotti V, Wei H, Jonsdottir GA, Stewart R, Thomson JA. Whole-genome analysis of histone H3 lysine 4 and lysine 27 methylation in human embryonic stem cells. Cell Stem Cell. 2007;1:299-312.

5. Zhao XD, Han X, Chew JL, Liu J, Chiu KP, Choo A, Orlov YL, Sung WK, Shahab A, Kuznetsov VA, Bourque G, Oh S, Ruan Y, Ng HH, Wei CL. Wholegenome mapping of histone $\mathrm{H} 3$ Lys4 and 27 trimethylations reveals distinct genomic compartments in human embryonic stem cells. Cell Stem Cell. 2007;1:286-98

6. Voigt $P$, Tee WW, Reinberg D. A double take on bivalent promoters. Genes Dev. 2013;27:1318-38.

7. Pursani V, Pethe P, Bashir M, Sampath P, Tanavde V, Bhartiya D. Genetic and epigenetic profiling reveals EZH2-mediated down regulation of OCT4 involves NR2F2 during cardiac differentiation of human embryonic stem cells. Sci Rep. 2017;7:13051.

8. Henikoff S, Ahmad K. Assembly of variant histones into chromatin. Annu Rev Cell Dev Biol. 2005;21:133-53.

9. Takeuchi JK, Lou X, Alexander JM, Sugizaki H, Delgado-Olguín P, Holloway AK, Mori AD, Wylie JN, Munson C, Zhu Y, Zhou YQ, Yeh RF, Henkelman RM, Harvey RP, Metzger D, Chambon P, Stainier DY, Pollard KS, Scott IC, Bruneau BG. Chromatin remodelling complex dosage modulates transcription factor function in heart development. Nat Commun. 2011;2:187.

10. Bertero A, Madrigal P, Galli A, Hubner NC, Moreno I, Burks D, Brown S, Pedersen RA, Gaffney D, Mendjan S, Pauklin S, Vallier L. Activin/nodal signaling and NANOG orchestrate human embryonic stem cell fate decisions by controlling the H3K4me3 chromatin mark. Genes Dev. 2015;29: 702-17.

11. Liu L, Jin G, Zhou X. Modeling the relationship of epigenetic modifications to transcription factor binding. Nucleic Acids Res. 2015;43:3873-85.

12. Kawamura T, Ono K, Morimoto T, Wada H, Hirai M, Hidaka K, Morisaki T, Heike T, Nakahata T, Kita T, Hasegawa K. Acetylation of GATA-4 is involved in the differentiation of embryonic stem cells into cardiac myocytes. J Biol Chem. 2005;280:19682-8.

13. Durocher D, Charron F, Warren R, Schwartz RJ, Nemer M. The cardiac transcription factors Nkx2-5 and GATA-4 are mutual cofactors. EMBO J. 1997; 16:5687-96.

14. Stennard FA, Harvey RP. T-box transcription factors and their roles in regulatory hierarchies in the developing heart. Development. 2005;132: 4897-910.
15. Miller SA, Mohn SE, Weinmann AS. Jmjd3 and UTX play a demethylaseindependent role in chromatin remodeling to regulate T-box family member-dependent gene expression. Mol Cell. 2010;40:594-605.

16. Seenundun S, Rampalli S, Liu QC, Aziz A, Palii C, Hong S, Blais A, Brand M, Ge K, Dilworth FJ. UTX mediates demethylation of H3K27me3 at musclespecific genes during myogenesis. EMBO J. 2010;29:1401-11.

17. Lee S, Lee JW, Lee SK. UTX, a histone H3-lysine 27 demethylase, acts as a critical switch to activate the cardiac developmental program. Dev Cell. 2012;22:25-37.

18. Chen JN, Fishman MC. Zebrafish tinman homolog demarcates the heart field and initiates myocardial differentiation. Development. 1996;122:380916.

19. Habets PE, Moorman AF, Clout DE, van Roon MA, Lingbeek $M$, van Lohuizen M, Campione M, Christoffels VM. Cooperative action of Tbx2 and Nkx2.5 inhibits ANF expression in the atrioventricular canal: implications for cardiac chamber formation. Genes Dev. 2002;16:1234-46.

20. Moskowitz IP, Kim JB, Moore ML, Wolf CM, Peterson MA, Shendure J, Nobrega MA, Yokota Y, Berul C, Izumo S, Seidman JG, Seidman CE. A molecular pathway including Id2, Tbx5, and Nkx2-5 required for cardiac conduction system development. Cell. 2007;129:1365-76.

21. Prall OW, Menon MK, Solloway MJ, Watanabe Y, Zaffran S, Bajolle F, Biben C, McBride JJ, Robertson BR, Chaulet H, Stennard FA, Wise N, Schaft D, Wolstein O, Furtado MB, Shiratori H, Chien KR, Hamada H, Black BL, Saga Y, Robertson EJ, Buckingham ME, Harvey RP. An Nkx2-5/Bmp2/Smad1 negative feedback loop controls heart progenitor specification and proliferation. Cell. 2007;128:947-59.

22. Bruneau BG. Signaling and transcriptional networks in heart development and regeneration. Cold Spring Harb Perspect Biol. 2013;5:a008292.

23. Jenuwein $T$, Laible $G$, Dorn R, Reuter G. SET domain proteins modulate chromatin domains in eu- and heterochromatin. Cell Mol Life Sci. 1998;54: 80-93.

24. Singer MS, Kahana A, Wolf AJ, Meisinger LL, Peterson SE, Goggin C, Mahowald M, Gottschling DE. Identification of high-copy disruptors of telomeric silencing in Saccharomyces cerevisiae. Genetics. 1998;150:613-32.

25. Feng $\mathrm{Q}$, Wang $\mathrm{H}, \mathrm{Ng} \mathrm{HH}$, Erdjument-Bromage $\mathrm{H}$, Tempst $\mathrm{P}$, Struhl $\mathrm{K}$, Zhang Y. Methylation of H3-lysine 79 is mediated by a new family of HMTases without a SET domain. Curr Biol. 2002;12:1052-8.

26. van Leeuwen F, Gafken PR, Gottschling DE. Dot1p modulates silencing in yeast by methylation of the nucleosome core. Cell. 2002;109:745-56.

27. Kim W, Kim R, Park G, Park JW, Kim JE. Deficiency of H3K79 histone methyltransferase Dot1-like protein (DOT1L) inhibits cell proliferation. J Biol Chem. 2012;287:5588-99.

28. Farooq Z, Banday S, Pandita TK, Altaf M. The many faces of histone H3K79 methylation. Mutat Res Rev Mutat Res. 2016;768:46-52.

29. Altaf M, Utley RT, Lacoste N, Tan S, Briggs SD, Cote J. Interplay of chromatin modifiers on a short basic patch of histone $\mathrm{H} 4$ tail defines the boundary of telomeric heterochromatin. Mol Cell. 2007:28:1002-14.

30. Onishi M, Liou GG, Buchberger JR, Walz T, Moazed D. Role of the conserved Sir3-BAH domain in nucleosome binding and silent chromatin assembly. Mol Cell. 2007;28:1015-28.

31. $\mathrm{Ng} \mathrm{HH}$, Ciccone DN, Morshead KB, Oettinger MA, Struhl K. Lysine-79 of histone $\mathrm{H} 3$ is hypomethylated at silenced loci in yeast and mammalian cells: a potential mechanism for position-effect variegation. Proc Natl Acad Sci. 2003;100:1820-5

32. Okada $Y$, Feng $Q$, Lin $Y$, Jiang $Q$, Li Y, Coffield VM, Su L, Xu G, Zhang Y. hDOT1L links histone methylation to leukemogenesis. Cell. 2005;121:167-78.

33. Steger DJ, Lefterova MI, Ying L, Stonestrom AJ, Schupp M, Zhuo D, Vakoc AL, Kim JE, Chen J, Lazar MA, Blobel GA, Vakoc CR. DOT1L/KMT4 recruitment and $\mathrm{H} 3 \mathrm{~K} 79$ methylation are ubiquitously coupled with gene transcription in mammalian cells. Mol Cell Biol. 2008;28:2825-39.

34. Wang Z, Zang C, Rosenfeld JA, Schones DE, Barski A, Cuddapah S, Cui K, Roh TY, Peng W, Zhang MQ, Zhao K. Combinatorial patterns of histone acetylations and methylations in the human genome. Nat Genet. 2008;40: 897-903.

35. Barry ER, Krueger W, Jakuba CM, Veilleux E, Ambrosi DJ, Nelson CE, Rasmussen TP. ES cell cycle progression and differentiation require the action of the histone methyltransferase Dot1L. Stem Cells. 2009;27:1538-47.

36. Schulze JM, Jackson J, Nakanishi S, Gardner JM, Hentrich T, Haug J, Johnston M, Jaspersen SL, Kobor MS, Shilatifard A. Linking cell cycle to histone modifications: SBF and $\mathrm{H} 2 \mathrm{~B}$ monoubiquitination machinery and cell-cycle regulation of H3K79 dimethylation. Mol Cell. 2009;35:626-41. 
37. Feng $Y$, Yang $Y$, Ortega MM, Copeland JN, Zhang M, Jacob JB, Fields TA, Vivian JL, Fields PE. Early mammalian erythropoiesis requires the Dot1L methyltransferase. Blood. 2010;116:4483-91.

38. Nguyen AT, Zhang Y. The diverse functions of Dot1 and H3K79 methylation. Genes Dev. 2011;25:1345-58.

39. Cattaneo P, Kunderfranco P, Greco C, Guffanti A, Stirparo GG, Rusconi F, Rizzi R, Di Pasquale E, Locatelli SL, Latronico MV, Bearzi C, Papait R, Condorelli G. DOT1L-mediated H3K79me2 modification critically regulates gene expression during cardiomyocyte differentiation. Cell Death Differ. 2016;234:555-64.

40. Kumar N, Hinduja I, Nagvenkar P, Pillai L, Zaveri K, Mukadam L, Telang J, Desai S, Mangoli V, Mangoli R, Padgaonkar S, Kaur G, Puri C, Bhartiya D. Derivation and characterization of two genetically unique human embryonic stem cell lines on in-house-derived human feeders. Stem Cells Dev. 2009;18:435-45.

41. Pawani $H$, Nagvenkar $P$, Pethe $P$, Bhartiya D. Differentiation of human ES cell line KIND-2 to yield tripotent cardiovascular progenitors. In Vitro Cell Dev Biol Anim. 2013;49:82-93.

42. Thorvaldsdottir H, Robinson JT, Mesirov JP. Integrative Genomics Viewer (IGV): high-performance genomics data visualization and exploration. Brief Bioinform. 2013;14:178-92.

43. Schubeler D, MacAlpine DM, Scalzo D, Wirbelauer C, Kooperberg C, van Leeuwen F, Gottschling DE, O'Neill LP, Turner BM, Delrow J, Bell SP, Groudine M. The histone modification pattern of active genes revealed through genome-wide chromatin analysis of a higher eukaryote. Genes Dev. 2004;18:1263-71.

44. Barski A, Cuddapah S, Cui K, Roh TY, Schones DE, Wang Z, Wei G, Chepelev I, Zhao K. High-resolution profiling of histone methylations in the human genome. Cell. 2007;129:823-37.

45. Stulemeijer IJ, Pike BL, Faber AW, Verzijlbergen KF, van Welsem T, Frederiks F, Lenstra TL, Holstege FC, Gasser SM, van Leeuwen F. Dot1 binding induces chromatin rearrangements by histone methylation-dependent and -independent mechanisms. Epigenetics Chromatin. 2011;4:2.

46. Lin YH, Kakadia PM, Chen Y, Li YQ, Deshpande AJ, Buske C, Zhang KL, Zhang Y, Xu GL, Bohlander SK. Global reduction of the epigenetic H3K79 methylation mark and increased chromosomal instability in CALM-AF10positive leukemias. Blood. 2009;114:651-8.

47. Jones B, Su H, Bhat A, Lei H, Bajko J, Hevi S, Baltus GA, Kadam S, Zhai H, Valdez R, Gonzalo S, Zhang Y, Li E, Chen T. The histone H3K79 methyltransferase Dot1L is essential for mammalian development and heterochromatin structure. PLoS Genet. 2008;4:e1000190.

48. Beltrami CA, Di Loreto C, Finato N, Rocco M, Artico D, Cigola E, Gambert SR, Olivetti G, Kajstura J, Anversa P. Proliferating cell nuclear antigen (PCNA), DNA synthesis and mitosis in myocytes following cardiac transplantation in man. J Mol Cell Cardiol. 1997;29:2789-802.

49. Zaidi S, Choi M, Wakimoto H, Ma L, Jiang J, Overton JD, Romano-Adesman A, Bjornson RD, Breitbart RE, Brown KK, Carriero NJ, Cheung YH, Deanfield J, DePalma S, Fakhro KA, Glessner J, Hakonarson H, Italia MJ, Kaltman JR, Kaski J, Kim R, Kline JK, Lee T, Leipzig J, Lopez A, Mane SM, Mitchell LE, Newburger JW, Parfenov M, Pe'er I, Porter G, Roberts AE, Sachidanandam R, Sanders SJ, Seiden HS, State MW, Subramanian S, Tikhonova IR, Wang W, Warburton D, White PS, Williams IA, Zhao H, Seidman JG, Brueckner M, Chung WK, Gelb BD, Goldmuntz E, Seidman CE, Lifton RP. De novo mutations in histone-modifying genes in congenital heart disease. Nature. 2013:498:220-3.

50. Wan X, Liu L, Ding X, Zhou P, Yuan X, Zhou Z, Hu P, Zhou H, Li Q, Zhang S, Xiong $S$, Zhang Y. MII2 controls cardiac lineage differentiation of mouse embryonic stem cells by promoting H3K4me3 deposition at cardiac-specific genes. Stem Cell Rev. 2014;10:643-52.

51. Nimura K, Ura K, Shiratori H, Ikawa M, Okabe M, Schwartz RJ, Kaneda Y. A histone $\mathrm{H} 3$ lysine 36 trimethyltransferase links Nkx2-5 to Wolf-Hirschhorn syndrome. Nature. 2009;460:287-91.

52. Kasahara $H$, Wakimoto $H$, Liu M, Maguire $C T$, Converso KL, Shioi T, Huang WY, Manning WJ, Paul D, Lawitts J, Berul Cl, Izumo S. Progressive atrioventricular conduction defects and heart failure in mice expressing a mutant Csx/Nkx2.5 homeoprotein. J Clin Invest. 2001;108:189-201.

53. Takeda M, Briggs LE, Wakimoto H, Marks MH, Warren SA, Lu JT, et al. Slow progressive conduction and contraction defects in loss of Nkx2-5 mice after cardiomyocyte terminal differentiation. Lab Invest. 2009;89:983-93.
54. Terada R, Warren S, Lu JT, Chien KR, Wessels A, Kasahara H. Ablation of Nkx2-5 at mid-embryonic stage results in premature lethality and cardiac malformation. Cardiovasc Res. 2011;91:289-99.

55. Pashmforoush M, Lu JT, Chen H, Amand TS, Kondo R, Pradervand S, Evans SM, Clark B, Feramisco JR, Giles W, Ho SY, Benson DW, Silberbach M, Shou W, Chien KR. Nkx2-5 pathways and congenital heart disease; loss of ventricular myocyte lineage specification leads to progressive cardiomyopathy and complete heart block. Cell. 2004;117:373-86.

56. Costa MW, Guo G, Wolstein O, Vale M, Castro ML, Wang L, Otway R, Riek P, Cochrane N, Furtado M, Semsarian C, Weintraub RG, Yeoh T, Hayward C, Keogh A, Macdonald P, Feneley M, Graham RM, Seidman JG, Seidman CE, Rosenthal N, Fatkin D, Harvey RP. Functional characterization of a novel mutation in NKX2-5 associated with congenital heart disease and adultonset cardiomyopathy. Circ Cardiovasc Genet. 2013;6:238-47.

57. Yuan F, Qiu XB, Li RG, Qu XK, Wang J, Xu YJ, Liu X, Fang WY, Yang YQ, Liao DN. A novel NKX2-5 loss-of-function mutation predisposes to familial dilated cardiomyopathy and arrhythmias. Int J Mol Med. 2015;35:478-86.

58. Hanley A, Walsh KA, Joyce C, McLellan MA, Clauss S, Hagen A, Shea MA, Tucker NR, Lin H, Fahy GJ, Ellinor PT. Mutation of a common amino acid in NKX2.5 results in dilated cardiomyopathy in two large families. BMC Med Genet. 2016;17:83.

59. Chen CW, Armstrong SA. Targeting DOT1L and HOX gene expression in MLL-rearranged leukemia and beyond. Exp Hematol. 2015;43:673-84.

\section{Submit your next manuscript to BioMed Central and we will help you at every step:}

- We accept pre-submission inquiries

- Our selector tool helps you to find the most relevant journal

- We provide round the clock customer support

- Convenient online submission

- Thorough peer review

- Inclusion in PubMed and all major indexing services

- Maximum visibility for your research

Submit your manuscript at www.biomedcentral.com/submit 